\title{
EL CASO TLATLAYA: \\ “Pan y Palos" en la región de Tierra Caliente en México
}

\author{
Francisco MARCOS MARTÍNEZ ${ }^{1}$; Fredy TORRES OREGÓN ${ }^{2}$ \\ ${ }^{1}$ Universidad Iberoamericana. ${ }^{2}$ Universidad Autónoma del Estado de México (México) \\ marcofranky2000@yahoo.com.,mx, zancamx@yahoo.com.mx
}

THE TLATLAYA CASE: "Bread and Sticks" in the region of "Tierra Caliente" in Mexico

Resumen: El presente documento refiere sobre palabras maestras como: encubrimiento, impunidad, corrupción, violación a la ley y a los derechos humanos como práctica subrepticia de una masacre -consumado por efectivos del Ejército-en Tlatlaya, Estado de México. La resolución de los aparatos de justicia gubernamentales apelaban a un enfrentamiento; sin embargo, las evidencias mostraron la aniquilación de los presuntos delincuentes. Asimismo, este municipio se ubica en la región sur de México en donde el Ejército tiene contacto con la población a través de programa del gobierno federal: SINHAMBRE, con el supuesto de ser una política social que busca una solución estructural de la pobreza extrema de alimentación en México.

Abstract: This document refers to key words such as: concealment, impunity, corruption, and violation of law and human rights as surreptitious practice of slaughter -accomplished by members of the army in Tlatlaya-, State of Mexico. The resolution of the apparatus of government justice appealed to a confrontation; however, the evidence showed the annihilation of suspects. Also, this municipality is located in the southern region of Mexico where the Army has contact with the public through the federal government's program: SINHAMBRE, with the assumption being a social policy that seeks a structural solution supply extreme poverty in Mexico.

Palabras clave: Masacre, Delincuencia, Enfrentamiento, Alimentación, Impunidad Massacre, Crime, Conflict, Alimentation, Impunity 


\section{Introducción}

La presión de organismos internacionales, de los medios de comunicación, la declaración de una testigo presencial y el peritaje de fotografías, permiten que las palabras maestras que tratan de legitimar una verdad instituida en un supuesto "enfrentamiento" en el -Caso Tlatlaya- se erosione y dé paso a una nueva fase de verdad instaurada desde otro enfoque que sostiene una "masacre" de los hechos. Por ello, el presente ensayo tiene como propósito describir y analizar el "enfrentamiento" y/o "masacre" de 22 personas por efectivos del Ejército mexicano en el municipio de Tlatlaya en el Estado de México. Aunado a esto, se presentan las estrategias de alimentación en la región de Tierra Caliente por parte del gobierno federal, incluye al municipio de Tlatlaya.

\section{Enfrentamiento y/o masacre}

El Estado mexicano para enfrentar al crimen organizado hace uso del Ejército, la Marina, la Policía Federal y la Gendarmería, cuerpos de seguridad que se encuentran distribuidos en distintas regiones del territorio nacional. No obstante, el Ejército se ha relacionado con sucesos de corte criminal en la realización de sus tareas de combate a la delincuencia. Relativo a ello, un acontecimiento que sucedió al sur del Estado de México sobre un enfrentamiento entre efectivos del Ejército y presuntos delincuentes. Méndez (2014) recupera el comunicado de la Secretaría de la Defensa Nacional (SEDENA), sostiene: "que aproximadamente a las 5:30 horas, en inmediaciones del poblado Cuadrilla Nueva, municipio de Tlatlaya, personal militar al realizar un reconocimiento terrestre, ubicó una bodega que se encontraba custodiada por personas armadas, mismas que al percatarse de la presencia de las tropas abrieron fuego, por lo que el personal castrense repelió dicha agresión". Igual, añadió que los 22 presuntos agresores -21 hombres y una mujer- murieron tras el choque armado. En el sitio se aseguraron 21 armas largas, 16 fusiles AK-47, 6 fusiles AR-15, un fusil marca Calico, 2 escopetas, 13 armas cortas y un revolver 38 especial, así como una granada de fragmentación, 112 cargadores y cartuchos útiles. Además, se liberaron a tres mujeres quienes manifestaron estar secuestradas, las cuales fueron puestas a disposición de las autoridades en calidad de presentadas y quedaron a disposición del agente del Ministerio Público (MP) de la federación, así como el armamento y las municiones aseguradas. Es pertinente aclarar que los medios de comunicación e instituciones refieren a San Pedro Limón como lugar en donde ocurrió el supuesto enfrentamiento.

La agencia de noticias estadounidense Associated Press (AP) enuncia que los muertos -del caso Tlatlaya- pudieron haber muerto por abatimiento. Ante esa información, la Organización no Gubernamental (ONG) internacional Human Rights Watch (HRW) pidió al gobierno de Peña Nieto "una investigación imparcial y efectiva". El tema se reactivó cuando la revista Esquire buscó a la revista Proceso para publicar conjuntamente, en sus respectivas páginas electrónicas, en el que una testigo de los hechos confirmó que 21 de los muertos fueron ejecutados cuando ya se habían rendido y depuesto las armas. Igual, Amnistía Internacional (AI) pidió al gobierno de México una investigación exhaustiva e imparcial de la muerte de las 22 personas, entre las que había una adolescente de 15 años (Carrasco, 2014-a). La ONU se sumó a la presión internacional y pidió protección para la testigo que acusó de asesinato al cuerpo castrense. El relator especial Christof Heyns sostuvo que el gobierno de México tiene la obligación de investigar a fondo, juzgar y sancionar todos los presuntos casos de ejecuciones extralegales, arbitrarios o sumarios (AFP; 2014). La testigo presencial aseguró que se trató de una ejecución por parte del Ejército. Refiere que los soldados dispararon primero y los presuntos delincuentes respondieron el ataque; uno de ellos murió y los demás se rindieron. Los militares interrogaron a los 21 hombres y después los ejecutaron (Martínez, 2014). La testigo puntualiza: 


\begin{abstract}
“ellos (los soldados decían que se rindieran y los muchachos decían que les perdonaran la vida. Entonces (los soldados) dijeron '¿no que muy machitos, hijos de su puta madre? ¿No que muy machitos?'. Así les decían los militares cuando ellos salieron (de la bodega). Todos salieron. Se rindieron, definitivamente se rindieron. [...] Entonces les preguntaban cómo se llamaban y los herían, no los mataban. Yo decía que no lo hicieran, que no lo hicieran, y ellos decían que 'esos perros no merecen vivir'. [...] Luego los paraban así en hilera y los mataban. [...] Estaba un lamento muy grande en la bodega, se escuchaban los quejidos" (Carrasco, 2014-a).
\end{abstract}

La testigo aseveró que los muertos, entre ellos su hija de 15 años, fueron ejecutados a sangre fría (AFP; 2014). Lo anterior coincide con lo documentado por Cervantes (2014), en donde vecinos del lugar refieren que los hechos sucedieron de las 4:00 a las 5:30 de la mañana tiempo en que escucharon ráfagas y luego disparos huecos.

Contra su voluntad, el gobierno mexicano ha tenido que actuar ante las crecientes evidencias de una posible matanza de civiles perpetrado por el Ejército, pero se encamina a culpar a "soldados desobedientes" para evadir cualquier responsabilidad política. La SEDENA se vio obligada a informar, luego de que la administración de Barack Obama hiciera una declaración pública en la que pidió al gobierno de Peña Nieto una investigación verídica de lo ocurrido en el caso Tlatlaya (Carrasco, 2014). La rendición de cuentas que exige el gobierno de Estados Unidos responde a los 1000 millones de dólares que entregó a México como ayuda para fortalecer sus fuerzas para combate al narcotráfico, por lo que ha pedido una revisión creíble del caso a las autoridades civiles (AFP, 2014).

La SEDENA empeñado en sostener el abatimiento o enfrentamiento con presuntos delincuentes durante un patrullaje militar, indicó que la intervención de la justicia castrense era independiente de las investigaciones de la Subprocuraduría Especializada en Investigación de Delincuencia Organizada de la Procuraduría General de la República (PGR) y de la Comisión Nacional de los Derechos Humanos (CNDH). En lo que respecta al gobierno mexiquense, luego de guardar hermetismo durante 24 horas de los hechos ocurridos en Tlatlaya, Eruviel Ávila Villegas -gobernador del Estado de México- habla de un enfrentamiento. Explicó que el Ejército tuvo una valiente presencia y acción al poder rescatar a tres personas que estaban secuestradas y, puntualizó que "los elementos de las fuerzas armadas actuaron con firmeza y en su legítima defensa abatieron a los delincuentes y que el Ejército mexicano seguirá apoyando las labores de seguridad que implementa su administración, así como a los gobiernos de los ayuntamientos locales" (Ramón, 2014). Miguel Ángel Osorio Chong -Secretario de Gobernación- señaló que "México tiene un gran Ejército y si existiera un señalamiento negativo en torno a los militares, sería una excepción”, también explicó que el caso Tlatlaya nunca fue cerrado en la PGR como sí lo hiciera la CNDH (Garduño, 2014).

La puesta en escena por la SEDENA, secundada tanto por el gobierno del Estado de México como por la CNDH del supuesto enfrentamiento entre elementos del Ejército con los delincuentes se ha erosionado. "Enfrentamiento", "delincuentes", "legítima defensa" y "abatimiento", fueron las palabras maestras de suma regularidad de estas instituciones. En perspectiva de Balibar (1995: 59) "las palabras maestras son las mediadoras inevitables de la organización de la experiencia en relación con el discurso en el que ellas mismas figuran, las mediadoras de la relación entre los sujetos y los objetos, entre los objetos entre sí, y entre los sujetos entre sí, en un solo nudo de sentido". De igual modo, el autor puntualiza que la función de las palabras maestras es la de ser invocadas en privado o en público a título de garantía o de fundamento para la veracidad, la autenticidad, la validez de un discurso, de una práctica, de un tipo de vida, de un obra; es decir, como principios de afirmación de las verdades, y como criterios de distinción de lo verdadero y de lo no verdadero. Efecti- 
vamente, después de haberse consumado la masacre de Tlatlaya desde el comunicado del Ejército mexicano, la explicación del gobierno del Estado de México hasta el veredicto final de la CNDH, todos apuntaban hacia una direccionalidad de verdad, certeza, certidumbre, objetividad, autenticidad y veracidad de los hechos sobre un enfrentamiento. Sin embargo, el desfallecimiento total de los presuntos delincuentes y del bando del cuerpo castrense solo un miembro resultara herido generaba demasiada incertidumbre.

Javier Hernández Valencia, -representante de la Oficina del Alto Comisionado de Naciones Unidas para los Derechos Humanos- manifiesta que la ejecución de 22 personas en Tlatlaya, es sólo un caso de un conjunto más grande de crímenes cometidos por soldados y policías que no han provocado una reacción del Estado (Garduño y Méndez, 2014). En este sentido, Castillo (2014) da cuenta que en 2008, en San pedro Limón, 20 hombres armados y vestidos con ropa tipo militar llegaron al tianguis del poblado y abrieron fuego contra la población que allí se encontraba. Arribaron a bordo de camionetas y supuestamente asesinaron a 23 personas. Llegaron al lugar otros vehículos ocupados por miembros del Ejército quienes retiraron los cadáveres, recogieron los casquillos y limpiaron la escena. Despojaron de sus teléfonos celulares a los espantados vecinos y visitantes y se las arreglaron para hacerles saber que era preferible que no se supiera nada de lo ocurrido. También, en 2013, la PGR ejecutó acción penal en contra de cuatro integrantes del 102 batallón por haber abatido a 4 funcionarios de Arcelia, en el estado de Guerrero, entre ellos: el director y subdirector de tránsito. Igual, el 102 batallón de infantería de la 22 zona militar, en 2011 llegó a Tejupilco y supuestamente dos militares fueron acusados de recibir sobornos del cartel de "La Familia michoacana". Cervantes (2014) alude que durante un recorrido en San Pedro Limón, no hubo comerciante que no dijera temer al gobierno y que están más tranquilos sabiendo que la maña (mafia, delincuencia organizada) está ahí, porque cuando aparece el gobierno, golpea a los jóvenes, los tortura y les roba sus cosas. No cabe duda que Tlatlaya es un espejo del México actual. Un muro de ladrillo gris con dos impactos de balas y dos manchas de sangre es la representación simbólica de un país en descomposición en el que la violencia ha alcanzado niveles demenciales de crueldad, sin límites ni control, producida no solo por los criminales, sino también por quienes tienen la responsabilidad de velar por la seguridad de la población (Tajonar, 2014). Las víctimas todos eran originarios de las entidades mexiquense y guerrerense cuya ocupación era campesina o empleados de comercios. Algunos estaban casados y eran padres de familia, sus familiares señalan que eran gente de bien pero levantada o secuestrada por el crimen organizado para obligarlos a servirles a sus propósitos (Cervantes, 2014).

Entre desapariciones, secuestros y asesinatos, Martínez (2014-a) con información del Registro Nacional de Datos de Personas Extraviadas o desaparecidas, de 2011 a la fecha han sido denunciadas 52, 941 personas no localizadas, extraviadas, ausentes o desaparecidas. De ese total han sido ubicadas 30,619 la mayoría con vida y 1,524 fallecidos. Asimismo, explica que en México, 22 mil 322 personas se encuentran actualmente en el estatus de no localizadas. De este número, 12, 532 corresponden a reportes presentados durante el último tramo del sexenio calderonista y 9, 790 se inscriben en hechos registrados durante la administración de Peña Nieto. Por su parte, González (2014) señala que en el año 2013, en México, un promedio de 62 personas fueron asesinadas por día, por lo que sumaron 22 mil 732 casos, según informe del Instituto Nacional de Estadística Geografía e Informática (INEGI). En 2012 fueron 70 por día. El Estado de México concentró el mayor número de asesinatos de 2013, con 3,485, equivalente al 14.4\% del total, Guerrero 2,203, Chihuahua 1,485 (González, 2014).

\section{La caída del supuesto enfrentamiento}

En lo relativo al caso Tlatlaya, las fotografías obtenidas de forma anónima por la agencia 
de noticias MVT se les realizó un dictamen pericial, trabajo efectuado por el criminólogo José Luis Mejía Contreras (Castillo, 2014-a) y concluyó en lo siguiente:

Catorce de las 22 personas abatidas por efectivos del Ejército fueron colocadas a menos de un metro de las paredes de una bodega y los militares les dispararon a corta distancia. Para que un impacto de bala - de fusiles M-1- deje un boquete en una pared luego de atravesar un cuerpo, se dispara a menos de $30 \mathrm{~cm}$ de la víctima.

La escena fue totalmente manipulada; hubo cuerpos sembrados y desaparecieron evidencias. Ninguno de los delincuentes abatidos tiene disparos en la cabeza. Si la confrontación fue entre quienes estaban dentro y los militares fuera de la bodega, había una distancia de entre 20 y 30 metros entre unos y otros, por lo que cualquier disparo de los militares se tuvo que alojar en el cadáver, ya que ningún arma es capaz de atravesar un cuerpo y luego impactar en la pared y dejar un boquete.

Las imágenes corresponden a momentos en los cuales los cuerpos y las armas que supuestamente se utilizaron para agredir a los militares no habían sido levantadas por la Procuraduría General de Justicia del Estado de México (PFJEM), y en ningún momento los peritos colocaron letreros que indicaran la existencia de casquillos de cartuchos percutidos por las víctimas.

Todos los disparos se registraron a la altura del pecho y el abdomen. Las 14 personas fueron colocadas de pie, en las fotografías se observa que en cada caso se percutieron dos disparos a una altura de 1.20 y 1.40 metros.

Uno de los datos periciales más relevantes es que todas las víctimas presentan manchas de lodo en las rodillas, otras en el pecho y luego aparecen tirados sobre piedra en un terreno totalmente seco. A esas personas las sometieron, permanecieron más de media hora hincadas, algunas de pecho tierra, luego quizá los pusieron de pie y entonces les dispararon a menos de $30 \mathrm{~cm}$, lo que provocó que los cuerpos fueran atravesados y las ojivas impactaran contra las paredes dejando un gran hueco.

Nadie muere en un enfrentamiento con las piernas cruzadas porque la dinámica del movimiento que se presenta cuando alguien cae abatido en un intercambio de disparos registra el llamado trompo; es decir, el cuerpo gira hacia el lado contrario del que recibió el impacto de bala. En la escena que se observa en las fotografías más de cinco cuerpos cayeron totalmente de espaldas, uno más de frente, pero en ninguno se observa el giro natural que se presenta al recibir un impacto de bala de grueso calibre a más de 20 metros de distancia, lo que evidencia que esas personas fueron sacrificadas en un sitio y luego arrastradas al lugar donde se montó la escena, y a todos los tiraron de espaldas para hacer creer que así cayeron, lo cual es imposible.

En el lugar había tres camionetas que supuestamente utilizaron para disparar contra los militares y resguardarse de los tiros de estos, pero los vehículos no presentan daños graves. Incluso tres de los cuerpos fueron colocados por delante de las puertas abiertas de los vehículos, como si en lugar de protegerse trataran de impedir que las balas perforaran la carrocería.

Sobre el supuesto sitio para mantener a personas privadas de su libertad considera que nadie tiene secuestrada a una persona en esas condiciones.

No existe una lógica en el tipo de armamento que plantaron en los cadáveres, mientras las armas son negras, los cargadores son grises y esos sólo los utilizan los militares. En muchos casos las armas aparecen colocadas perfectamente alineadas con los cadáveres, aparentemente sostenidas o hasta los cargadores 
extras que supuestamente usarían las víctimas estaban en paralelo con los rifles (Castillo, 2014-b).

Bien, del caso Tlatlaya hay ocho militares detenidos por estos hechos. La SEDENA sostuvo que fueron puestos a disposición del juzgado sexto militar y recluidos en la prisión de la primera región militar, un oficial y siete elementos de tropa (Aranda, 2014-a). No obstante, esto generó molestia entre integrantes del Ejército, quienes en el anonimato de las redes sociales criticaron las actuaciones del alto mando castrense y de la CNDH. Entre sus expresiones: "un superior siempre va al frente de sus hombres, siempre da la cara por sus hombres y no los entrega al matadero por querer quedar bien" (Aranda, 2014). De igual modo, se lanzó una convocatoria para una marcha -el 11 de octubre en la Ciudad de México- con la etiqueta \#yosoy26 para defender a los militares acusados. Los convocantes argumentaban que los soldados no pueden ser los únicos responsables porque solo hicieron su trabajo en cumplimiento de órdenes. El mismo argumento es utilizado por un grupo identificado en Facebook como esposas de militares mexicanos (Carrasco, 2014-b).

José Miguel Vivanco (de HRW) refiere que estamos ante una de las masacres más graves cometidas por el Ejército mexicano en los tiempos recientes. Lo preocupante no solo es la masacre, sino el esfuerzo de casi tres meses para encubrir estos hechos. Si no fuera por el periodismo y la presión internacional estaríamos ante la "porfiriada" versión oficial que intenta más bien evitar la justicia, distorsionar los hechos y proteger a los culpables. Vivanco añadió que todos aquellos que se prestaron para el encubrimiento deben responder por qué intentaron obstruir las investigaciones judiciales para garantizar la impunidad (Gómez, 2014). En efecto, Tlatlaya es el reflejo de múltiples rostros de un México consumido por la violencia y los vicios ancestrales del autoritarismo que busca renovarse a contracorriente de los avances democráticos: la ausencia de un auténtico estado de derecho, la manipulación política de la ley, el encubrimiento, la impunidad selectiva, la corrupción de la política, la connivencia del crimen organizado con la autoridades, la tensa complicidad entre el poder civil y las fuerzas armadas, el engaño y el control de la información operados desde la Dirección General de Comunicación Social de la Presidencia, la hipocresía de la responsabilidad compartida entre México y Estados Unidos en el combate al narcotráfico, la apuesta al olvido del horror ya cotidiano, en suma, la vesania del poder (Tajonar, 2014).

La dramaturgia de la SEDENA se ha desdibujado totalmente con la explicación de una testigo presencial de los hechos. Las palabras maestras - "enfrentamiento", "delincuentes", "legítima defensa" y "abatimiento"- emitidas y sostenidas por la SEDENA, el gobierno del Estado de México y de la CNDH se desvanecen; no obstante, otras palabras maestras como: "masacre", "encubrimiento", "impunidad" y "corrupción" se escuchan desde las ONG's y medios de comunicación hasta la ONU y AI y, a su vez legitiman una verdad distinta a la anterior. Es pertinente destacar la importancia de las imágenes o significantes de los hechos y la hermenéutica realizada por un perito en criminología que erosionan tanto las conclusiones del gobierno mexiquense como de la CNDH y del Ejército mexicano.

La supuesta verdad del caso Tlatlaya ha pasado de una arena planchada y encarpetada a otra arena de verdad. Este escenario representa una dialéctica de la verdad: con arreglos a fines y con arreglos a valores (Weber, 2012). En este sentido, Foucault (1995) manifiesta que hay dos historias de verdad. La primera es una especie de historia interna de la verdad que se corrige partiendo de sus principios de regulación: es la historia de la verdad tal como se hace en o partir de la historia de las creencias. Por otra parte, cree en la sociedad, o al menos en nuestras sociedades, hay otros sitios en los que forma la verdad, allí donde se definen un cierto número de reglas de juego, a partir de las cuales vemos nacer ciertas formas de subjetividad, dominios de objeto, tipos de saber y, por consiguiente, podemos hacer a partir de ello una historia externa, exterior, de la verdad. Los argumentos que utiliza para sostener su afirmación, son: 1) utiliza como explicación un problema de investigación judicial de 
la verdad en la Grecia arcaica. Trata de una carrera de carros desarrollado en un circuito con ida y vuelta, pasando por la baliza, en donde los organizadores habían colocado a una persona para observar la regularidad de la carrera. Se lleva a cabo la carrera, el perdedor no aceptó el resultado y, lleva al ganador a jurar ante Zeus que no cometió ninguna irregularidad. Entonces, el ganador acepta haber cometido dicha irregularidad. El testigo nunca se le pregunta nada. Esta es una forma de producir la verdad. 2) La historia de Edipo de Freud, una verdad elaborada desde el Psicoanálisis. Edipo para Foucault no es una verdad de naturaleza sino un instrumento de limitación y coacción que los psicoanalistas a partir de Freud, utilizan para contar el deseo y hacerlo entrar en una estructura familiar. Es una historia de poder. El autor se apoya en la ley de las mitades para refutar el triángulo edipico de Freud. Se trata del acoplamiento de mitades que se ajustan unos con otros. Así se elaboran pruebas de autenticidad. La mirada del testimonio es fundamental para la verdad. El derecho de dar testimonio. 3) La indagación como procedimiento a un sistema nacional de establecimiento de la verdad. Su aparición es un proceso político complejo y el análisis de las transformaciones políticas de la sociedad medieval. La indagación es una manera de ejercer el poder.

En el caso Tlatlaya , el testimonio de una testigo presencial, la indagación por parte de agentes externos y ajenos tanto del gobierno estatal como de la SEDENA y de la CNDH, la presión de organismos transnacionales y del gobierno de los Estados Unidos, factores fundamentales que erosionaron las palabras maestras afines al supuesto enfrentamiento. Sin embargo, las instituciones afirmantes de este suceso se resistían aceptar otra versión de los hechos, tanto así que, según Amnistía Internacional, la testigo fue presionada por representantes de la PGJEM y de la PGR para cambiar su testimonio y apoyar la versión de la SEDENA. En efecto, AI expuso que "cualquier acción oficial para desviar una investigación de los hechos con el fin de encubrir las violaciones graves de los derechos humanos y lograr la impunidad de los responsables, implica la colusión de estos funcionarios en los abusos" (Carrasco, 2014-a). La testigo forma parte de las tres mujeres supuestamente secuestradas y rescatadas; dos de ellas se encuentran sujetas a procesos penales y encarceladas por el delito de acopio de armas de fuego (Castillo, 2014-c). No cabe la menor duda que estamos ante actuaciones de encubrimiento e impunidad, esto se confirma aún más porque la PGJEM reservó por nueve años la información relacionada con sus investigaciones del caso, luego de que la agencia de noticias $A P$ realizara una solicitud de información pública (Castillo, 2014-c ).

Entre la persona que observó la regularidad de la carrera en la Grecia Arcaica y la testigo que presenció las ejecuciones sumarias en el caso Tlatlaya hay una gran diferencia; en el primer caso no se le tomó en cuenta; pero en el segundo su veredicto ha sido fundamental para ajusticiar a los elementos del Ejército, así como la generación de recomendaciones hacia el gobierno mexiquense por parte de la Comisión Nacional de los Derechos Humanos. Sin embargo, esto no exime al mandatario estatal tanto de encubrimiento como de la impunidad orquestada desde las instituciones gubernamentales y de ciertos poderes fácticos. Mucho menos su incapacidad de brindar seguridad a los ciudadanos que gobierna, el caso Tlatlaya es uno de los tantos crímenes que ocurren en el país, pero también es uno de los pocos que rompen la puesta en escena de la teatralidad judicial y de seguridad.

Cierto es que algunos de los jóvenes ejecutados fueron víctimas de la delincuencia organizada que los secuestró y enroló a sus filas contra su voluntad y víctimas del gobierno que los ejecutó. Doblemente víctimas. Sin embargo, esta realidad es una detonante que empieza a desnudar al "nuevo México" de Enrique Peña Nieto -presidente de México-. La imagen que su gobierno había difundido para cambiar la percepción de algunos sectores empresariales extranjeros surtía efecto porque ya se mostraban dispuestos en invertir en México. Sin embargo, los académicos: Mariene Braig -Universidad de Berlín-, Gunther Maihold -Universidad Libre de Berlín y Colmex- y Helene Balslev Clausen -Universidad de Aalsburg, Dinamarca-, sostenían que el "nuevo México" promovido por "Peña Nieto" se desvanece- 
ría en el aire porque no incluía a la sociedad civil, a la par de una visión integral que hiciera énfasis en la mejoría de las condiciones económicas, en especial de la clase trabajadora (Alcaraz y Appel, 2014). En efecto, el caso Tlatlaya fue uno de los detonantes que empezó a desvanecer el proyecto de nación del gobierno federal; a esto se suma el asesinato de seis personas en Iguala, Guerrero, de los cuales tres eran estudiantes normalistas, así como 43 alumnos víctimas de desaparición forzada por policías municipales en contubernio con el crimen organizado, acontecimientos que no solo se ha condenado en México sino también en distintas partes del mundo. Sin embargo, el presidente de México se mostró renuente a ceder y con voz autoritaria amenaza con el uso legítimo de las fuerzas del Estado para defender sus propósitos y legitimar su salvación a México. No obstante, ahora predominan las palabras: "El salvador que no lo fue".

\section{"Pan y palos" en la región de Tierra Caliente}

En el mismo sentido, las violaciones y ejecuciones perpetrados por las fuerzas militares contra presuntos delincuentes en Tlatlaya, así como la acción de los policías municipales y sicarios de narcotráfico contra normalistas de Ayotzinapa, las víctimas en ambos casos tienen un sello social que hoy más que nunca resalta por cada rincón del país: eran mayoritariamente jóvenes, pobres y del medio rural. Sector social que hoy se encuentra atrapado en un círculo de pobreza, un futuro incierto y amenazado por dos tipos de violencia: institucional, vía el gobierno, el cual con sus reformas y políticas de corte neoliberal para el campo sólo ha privilegiado a pequeños grupos empresariales agroindustriales, y en cambio, para los pobres rurales, ha dispuesto programas y apoyos asistenciales que perpetuán su control, dependencia, clientelismo y subordinación, como es caso de la reciente estrategia de la Cruzada contra el Hambre (SINHAMBRE). A la par de esta violencia vía dádivas y apoyos para los pobladores rurales, las comunidades rurales están siendo acosadas por el mismo gobierno en complicidad con empresas locales y trasnacionales para despojarlos, -sean por las buenas o malas- de sus recursos naturales. Tal violencia es explicada por Bartra cuando refiere los aportes teóricos de Foucault en su estudio sobre la microfísica de la opresión y sus luchas de resistencias en la historia de la humanidad: políticas, económicas y las rebeliones contra las formas de subjetividad impuestas (Bartra, 2013). En ese sentido, la violencia que ejerce hoy el Estado mexicano contra las comunidades rurales, que se erige en el papel de guía, el que va enfrente y abre a punta de machete la maleza para que sus patrones nacionales y extranjeros transiten libremente y despojen a las comunidades de sus recursos naturales con toda libertad. Tal despojo, corresponde o se encuadra en un marco más amplio del papel del capital trasnacional en el mundo, lo que, Bartra llama "violencia primaria crónica", pero que muchos antes Rosa Luxemburgo llamó "compulsiva expansión sobre una periferia precapitalista; acumulación originaria permanente" como dijo Samir Amin, y; “acumulación por desposesión” como la rebautizó David Harvey (Bartra, 2013).

Bien, las ejecuciones de pobladores rurales de Tlatlaya, los asesinatos de 6 jóvenes y desaparición de 43 normalistas de Ayotzinapa, es una mezcla de violencia política y económica, que refiere Foucault. Y más aún, violencia directa ejercida por el propio Estado en contubernio con grupos criminales a través de: asesinatos, extorsiones, secuestros, cobros de piso y amenazas, en amplias regiones de Guerrero, Michoacán y el sur del Estado de México. Tal ambiente de miedo y terror en la población ya ha provocado éxodos de campesinos que dejan tierras y bienes en manos de sus opresores. Como botón de muestra, en el Municipio de Técpan de Galeana, región Costa Grande, Guerrero, donde sicarios bajo las órdenes ya sean del cártel de los hermanos Beltrán Leyva, Familia Michoacana, Caballeros Templarios o del Cártel del Golfo [...] "tienen sometidos y aterrados a los habitantes de varias comunidades y pueblos, muchos de ellos abandonados y reducidos a cenizas. Pero el problema se agrava porque, según constató la revista Proceso en un recorrido por la zona, 
a las agresiones del crimen organizado se suman las del Ejército" (Díaz, 2013). Asimismo, 250 pobladores para salvar sus vidas, abandonaron tres comunidades serranas del municipio de San Miguel Totolapan, y se refugiaron en el municipio de Ajuchitlán del Progreso.

En lo relativo a Tlatlaya, en donde fuerzas militares en un supuesto "enfrentamiento" abatieron a los presuntos delincuentes en este municipio, al mismo tiempo se han involucrado e incorporado en programas sociales como es el caso de la estrategia de la Cruzada Nacional contra el Hambre dentro del "Programa Comedores Comunitarios". Los militares dentro de este programa capacitan y organizan a las mujeres de las comunidades beneficiadas de cómo preparar grandes raciones de alimentos para niños, adultos mayores, mujeres embarazadas y personas con alguna discapacidad, con dos raciones al día durante 5 días a la semana. En el Estado de México, de acuerdo al ejecutivo estatal, hasta la fecha se han incorporado 66 municipios, y de estos 64 se han instalado comedores comunitarios capacitados por el Ejército, que para el año 2014 se espera estén operando 2 mil comedores en beneficio de 240 mil personas (Gobierno del Estado de México, 2014). En el cuadro siguiente se expone el listado de los municipios y localidades de la entidad mexiquense en donde se han implementado los comedores comunitarios bajo el marco de SINHAMBRE:

Cuadro 1. Comedores comunitarios instalados en el Estado de México-SINHAMBRE.

\begin{tabular}{|c|c|c|c|}
\hline Municipio & $\begin{array}{c}\text { Número } \\
\text { Localidades } \\
\text { con Comedores } \\
\text { Comunitarios }\end{array}$ & Municipio & $\begin{array}{c}\text { Número } \\
\text { Localidades con } \\
\text { Comedores } \\
\text { Comunitarios }\end{array}$ \\
\hline Acambay & 102 & Acolman & 39 \\
\hline Almoloya & 104 & Aculco & 55 \\
\hline Atizapán de Zaragoza & 7 & Atlacomulco & 58 \\
\hline Chalco & 61 & Chicoloapan & 44 \\
\hline Cuautitlán Izcalli & 10 & Coacalco de Berriozábal & 34 \\
\hline Chimalhuacán & 6 & Donato Guerra & 31 \\
\hline Ecatepec de Morelos & 4 & Huehuetoca & 20 \\
\hline Ixtapaluca & 52 & Huixquilucan & 89 \\
\hline Ixtapan del Oro & 18 & Ixtapan de la sal & 29 \\
\hline Ixtlahuaca & 63 & Jilotepec & 66 \\
\hline Jipiquilco & 79 & Jocotitlán & 57 \\
\hline $\mathrm{LaPaz}$ & 18 & Lerma & 70 \\
\hline$\underline{\underline{\text { Luvianos }}}$ & 164 & Metepec & 57 \\
\hline Naucalpan de Juárez & 58 & Morelos & 30 \\
\hline Nezahualcóyotl & 7 & Ocuilan & 45 \\
\hline Nicolás Romero & 43 & El Oro & 42 \\
\hline San Felipe del Progreso & 104 & Otzoloapan & 41 \\
\hline san José del Rincón & 139 & San Mateo Atenco & 14 \\
\hline Sultepec & 80 & San simón de Guerrero & 17 \\
\hline Tecámac & 45 & Santo Tomás & 19 \\
\hline Tejupilco & 165 & Temascaltepec & 51 \\
\hline
\end{tabular}




\begin{tabular}{|c|c|c|c|}
\hline Temascalcingo & 66 & Tenango del Valle & 62 \\
\hline Temoaya & 63 & Texcaltitlán & 31 \\
\hline Tenancingo & 61 & Tianguistenco & 39 \\
\hline Texcoco & 70 & Tlatlaya & 87 \\
\hline Tlalnepantla de Baz & 5 & Tonatico & 13 \\
\hline Toluca & 100 & Tultepec & 46 \\
\hline Tultitlán & 11 & Valle de Bravo & 68 \\
\hline de Chalco & 7 & & 67 \\
\hline Solidaridad & 106 & Villa de Allende & 49 \\
\hline Villa Victoria & 56 & Villa Guerrero & 41 \\
\hline Zinancantepec & 30 & Zacualpan & 42 \\
\hline Zumpahuacán & & Zumpango & 58 \\
\hline
\end{tabular}

Fuente: información solicitada al Instituto de Transparencia y Acceso a la Información Pública del Estado de México y Municipios, Folio: 00046/SEDESEM/IP/2014, 10 diciembre 2014.

Del cuadro 1 destacan por el número de comedores instalados en algunos de los municipios rurales de mayor pobreza en el sur del Estado de México: Tejupilco, Luvianos y Tlatlaya, ubicados precisamente dentro de la zona llamada Tierra Caliente, que comparte con municipios de Guerrero y Michoacán, y conocida como una de las regiones más conflictivas, inseguras y violentas derivado de la actividad y presencia del narcotráfico. Precisamente, esta ha sido la justificación del Estado mexicano para llenar y ocupar temporal y permanentemente rancherías y localidades pobres de esta zona rural mexiquense por militares. Por ello, a pesar de que la inseguridad y violencia no ceden en esta región aún con la presencia del Ejército, el gobierno federal busca atemperar el descontento social y la pobreza de estos municipios con la puesta en marcha de comedores comunitarios, lo cual le permite vigilar y controlar a núcleos de población rural que ante el hartazgo de la pobreza, la violencia del narcotráfico, la intimidación y ocupación militar, no se insurreccionen contra el Estado. Es decir, estamos observando en México, que ante el descontento social de amplias capas de la sociedad, cansado de su situación social y económica, el gobierno hace uso del Ejército y otros cuerpos militares para sofocar y controlar la población.

En una reciente entrevista a un medio nacional el titular de la Secretaría de la Defensa Nacional así se refirió al papel de las fuerzas castrenses en SINHAMBRE enuncia que...en esta actividad los soldados están muy orgullosos de participar apoyando las decisiones del Gobierno de la República en la Cruzada Nacional contra el Hambre, es una estrategia de inclusión y bienestar y los municipios, los sectores público y privado así como organismos e instituciones internacionales (...) se coadyuva junto con las secretarías de Desarrollo Social de Salud y la Comisión Nacional para el Desarrollo de los Pueblos Indígenas en el establecimiento de comedores comunitarios en 28 municipios del Estado de Guerrero en el periodo comprendido de los meses de agosto a diciembre de 2013 [...] en las citadas actividades de labor social y establecimiento de comedores comunitarios participó un agrupamiento compuesto por personal especialista del servicio de ingenieros, médicos militares, odontólogos, promotores deportivos, 50 células de intendencia y maquinaria pesada; participaron también 4 unidades médicas dé la Secretaria de Salud. Las células de intendencia funcionaron de 10 a 15 días en cada localidad y capacitaron a mujeres en la elaboración, racionamiento y distribución de los alimentos (Vázquez, 2014). En este sentido, el hambre es una condición anormal de la vida de las sociedades que condicionan la acción institucional por un lado, y 
por el otro, obliga a los pobres ensayar diferentes tácticas se sobrevivencia (Torres, Herrera, Vizcarra y Lutz; 2015), sobre todo, cuando está en riesgo su propia seguridad.

En cambio, para la organización de derechos humanos Tlachinollan, A.C. en la montaña de Guerrero, -en entrevista a su titular-, señala: que el papel de las fuerzas armadas en la Cruzada contra el Hambre, en particular dentro de los Comedores Comunitarios, refiere que: para nosotros el uso del Ejército fue muy evidente que fue una acción de contrainsurgencia; es decir, son las nuevas formas de cómo usas el Ejército hasta para controlar el tema alimentario, por eso hubo muchas protestas, hubo actas de rechazo, en San Mateo, Municipio de Malinaltepec, levantaron una acta diciendo que ellos no querían la presencia del Ejército ni el Programa [...] porque coincide también [la presencia del Ejército] con la emergencia de las autodefensas, de la proliferación de grupos vinculados a la policía comunitaria; resurge Ayutla que siempre ha sido un foco rojo, donde hay autodefensas y policía comunitaria; aquí mismo en Olinalá, Temalacazingo, donde ha habido también presencia de grupos armados; en la parte de Costa Chica, de allá de San Luis [...] por eso si haces como un mapeo donde están las autodefensas y las policías comunitarias, donde fueron los levantamientos de insurgencia armada y donde se están ubicando los Comedores Comunitarios, [...] es eso, el control territorial del Ejército a través de un programa federal que es el tema alimentario, el control del estómago por parte del Ejército, ya controlas el cuerpo de la mujer a través de Oportunidades, y ahora buscas controlar a la comunidad a través del estómago [...] el Ejército toma el control de la alimentación, un derecho fundamental y que queda supeditado a que ahora los militares son cocineros [...] el Ejército empezó hacer recorridos, sirvió para tener una visión de cómo está el cultivo de la amapola [...] y también hubo una ubicación de quienes son los que están formando la policía comunitaria y cómo están trabajando (Tlalchinollan, 2014). Ante este estado de cosas, la situación que se vive en distintas regiones de México es de inseguridad, violencia, corrupción, muerte, secuestro, desapariciones, impunidad, simulación, injusticia, entre otros; que de antemano exige la reinvención del Estado mexicano y de las agendas públicas en los distintos niveles de gobierno.

\section{A manera de conclusión}

La posición y discurso de los titulares de las fuerzas armadas en México va quedando claro hacia donde se enfila el Estado mexicano respecto a temas como la pobreza, la violencia y derechos humanos, como ha quedado demostrado con el caso Tlatlaya que en Mayo de 2016 quedaron libres todos los militares acusados de dicho crimen. Los pobres de las zonas rurales y urbanas, principalmente jóvenes, serán combatidos o exterminados porque se conducen por vías violentas, interrumpen y agreden la normalidad que el Estado viene construyendo con el apoyo de las instituciones y la repetición incesante de discursos que alaban el papel del mercado, desarrollo y progreso. Por ello, aquellos sectores sociales que no se ajusten a las directrices que marca el Estado, sean éstas dadivas y programas que sólo atemperan la pobreza, serán vigilados y de ser necesario, sometidos.

En lo que respecta a la procuración de justicia en algunas instituciones del sistema judicial mexicano, así como de los derechos humanos padece de una profunda incompetencia. Esto quedó claramente ilustrado en el caso Tlatlaya. Encubrimiento, impunidad, corrupción, violación a la ley y a los derechos humanos ilustran la dramaturgia instituida por la SEDENA, a ello se une tanto los dictámenes periciales de la Procuraduría General de Justicia del Estado de México como el informe de la Comisión Nacional de los Derechos Humanos. El veredicto de los peritos criminólogos de la Procuraduría mexiquense responden a dos situaciones: uno, atienden las órdenes del gobierno y no a la ética profesional; dos, incompetencia profesional. Cualquiera que sea su realidad -del tiempo que lleva la presente administración de Eruviel Ávila- pone en duda los procedimientos tanto periciales como judiciales en materia de administración de justicia. El desplazamiento de las "pala- 
bras maestras" de la primera verdad, resultado de la puesta en escena de la SEDENA, sin duda pone en evidencia un incipiente aparato judicial, no solo en el Estado de México, sino en todo el país. Ante este estado de cosas surge la siguiente pregunta: ¿Cuántas puestas en escena ha realizado la SEDENA en su lucha contra el crimen organizado?.

México es una nación que sin duda puede salir avante de la situación que vive, siempre y cuando se modifiquen las estrategias (si es que las hay) tanto de programas sociales como combate al narcotráfico y crimen organizado. La simulación, corrupción, impunidad, clientelismo y caciquismo político, violación a la ley y a los derechos humanos, son palabras maestras que sobresalen en la realidad mexicana actual; sin embargo, para erosionar dichos signos lingüísticos es fundamental no solo reinventar el Estado mexicano, sino también las políticas públicas en todos los niveles, así como las instituciones gubernamentales y de la sociedad civil que de alguna manera se vinculan con la agenda pública. En tanto, para que esto suceda no solo será la voluntad del Estado, sino también con la presión de una sociedad activa y organizada que señale la directriz hacia un escenario alternativo, distante de la realidad contemporánea. El pueblo mexicano no requiere de puestas en escenas, mucho menos de actores políticos mesiánicos que apelan a una soteriología y a la fe, sino de un auténtico jefe de Estado con un proyecto de nación que permita tanto resarcir como reorientar el rumbo de esta nación.

\section{Bibliografía}

Alcaraz, Y. y Appel, M. 2014. “La quimera del nuevo México”, Revista Proceso, No. 1974: 19-21

Aranda, J. 2014. "Militares respaldan en redes sociales la actuación de sus compañeros en Tlatlaya", La jornada, Distrito Federal, no. 10833: 530 sep. P. 9 http://www.jornada.unam. $\mathrm{mx} / 2014 / 09 / 30 /$ politica/009n1pol

Aranda, J. 2014a. "Hay ocho militares detenidos por esos hechos", La jornada, no. 10829: 9

AFP, 2014. "Se suma la ONU a la exigencia de aclarar el caso Tlatlaya", La Jornada, No. 10833: 8

Balibar, E. 1995. Nombres y lugares de la verdad, Buenos Aires, Ediciones Nueva Visión

Balibar, E. 2005. Violencia, identidades y civilidad. Para una cultura política global, Barcelona, Gedisa editorial

Bartra, A. 2013. "Preámbulo: la modernidad bárbara", en Rodriguez Wallenius Carlos y Ramsés Arturo Cruz Arenas (coords.) El México bárbaro del siglo XXI, México, Universidad Autónoma Metropolitana - Universidad Autónoma de San Luis Potosí.

Castillo, G. 2014. "Segunda matanza de más de 20 en Tlatlaya que involucra a integrantes del ejército", La Jornada, Distrito Federal, no. 10831: 9

Castillo, G. 2014a. "En tres horas militares arreglaron sitio del enfrentamiento en Tlatlaya", La Jornada, Distrito Federal, no. 10830: 3

Castillo, G. 2014b. "Ultimadas a muy corta distancia, 14 de las víctimas de Tlatlaya", La jornada, Distrito Federal, no. 10829: 3

Castillo, G. 2014c. "La investigación de la PGR sobre el caso Tlatlaya partirá de cero", La Jornada, Distrito Federal, no. 10824: 5

Carrasco, J. 2014. "Caso Tlatlaya: la indisciplina militar que mató a 22 personas", Revista Proceso, sustraído: http://www.proceso.com.mx/?p=383212

Carrasco, J. 2014a. "Sólo Washinton logró “reabrir" el caso Tlatlaya”, Revista Proceso, Distrito Federal, no. 1977: 14-17

Carrasco, J. 2014b. "Batallón 102: un historial criminal", Revista Proceso, Distrito Federal, no. 1979: 16-21

Cervantes, J. 2014. "Eran buenos muchachos, la maña los levantó", Revista Proceso, Distrito Federal, no. 1980: 22-27

Díaz, G. 2013. "En Guerrero: muerte, miedo, éxodo, pueblos fantasmas", Revista Proceso, sustraído: http://www.proceso.com.mx/?p=330485

Foucault, M. 1995. La verdad y las formas jurídicas, Barcelona, Gedisa editorial

Foucault, M. 2005. Vigilar y castigar. Nacimiento de la prisión, México, siglo XXI editores

Garduño, R. y Méndez, E. 2014. "La matanza en Tlatlaya no es un caso aislado, subraya la ONU”, 
sustraído: http://www.jornada.unam.mx/ultimas/2014/11/06/la-matanza-en-tlatlaya-noes-un-caso-aislado-subraya-la-onu-1828.html

Garduño, R. 2014. "Si se comprueba ejecución en Tlatlaya, será sólo una acción aislada, dice Osorio Chong", La Jornada, Distrito Federal, no. 10830: 4

Gobierno del Estado de México, 2014. “Tercer Informe de Resultados”, sustraído: http://www.eruviel.com/wp-content/uploads/2014/09/3er_Informe_2014.pdf

Gómez, C. 2014. "Las fotografías publicadas por la Jornada fortalecen versión de ajusticiamiento: ONG", La Jornada, no. 10830: 5

González, S. 2014. "El año pasado, trágico para el país: hubo 62 muertes violentas por día, según INEGI", La Jornada, Distrito Federal, no. 10766: 11

Instituto de Transparencia y Acceso a la Información Pública del Estado de México y Municipios. 2014, Folio: 00046/SEDESEM/IP/2014.

Martínez, D. 2014. "Caso Tlatlaya, la matanza de narcos que divide a México", sustraído: noticias. terra.com.mx/mexico/caso-tlatlaya-la-matanza-de-narcos-que-divide-a mexico,fe8b8cc0c 25c8410VgnVCM3000009af154d0RCRD.html,

Martínez, F. 2014a. "No localizadas, 22 mil 322 personas en el país: subprocuradora Benítez”, $L a$ Jornada, Distrito Federal, no. 10795: 5

Méndez, A. 2014. "Enfrentamiento en Estado de México deja un saldo de 22 muertos", La Jornada, Distrito Federal, no 10743: 3

Ramón, R. 2014. "Reconoce Eruviel Ávila a Ejército por abatir a 22 presuntos plagiarios", sustraído: http://www.jornada.unam.mx/ultimas/2014/10/06/eruviel-avila-en-tlatlaya-si-hubo-unenfrentamiento-454.html

Tlalchinollan, 2014. Centro de Derechos Humanos de la Montaña, A.C., Tlapa de Comonfort, Guerrero.

Torres F., Herrera F., Vizcarra I., y Lutz B. (2015) "Etnografía institucional del proyecto estratégico de seguridad alimentaria (PESA) en una comunidad Mazahua", en la revista Nueva Antropología, Vol. XXVIII, Núm. 82, enero-junio, pp. 51-81.

Tajonar, H. 2014. "El espejo de Tlatlaya”, pp. 42-43, en la revista Proceso, no. 1980, 12 de octubre de 2014.

Vázquez, M. 2014. "Los soldados estamos muy orgullosos de participar en la Cruzada contra el Hambre afirma Salvador Cienfuegos", La Prensa, sustraído: http://www.sedesol.gob.mx/ work/models/SEDESOL/Sala_Prensa/Noticias/pdf/28032014-Soldados.pdf

Weber, M. 2012. Economía y sociedad, esbozo de Sociología comprensiva, México, FCE. 